\title{
Technical and Economic Assessment for Deployment of Distribution Automation Equipments - Enabling Self-Healing Strategies
}

\author{
Roberto Moreira, Student Member, IEEE, Nuno Silva, Member, IEEE and Hélder Leite
}

\begin{abstract}
This paper presents a methodology to evaluate technical and economic benefits achieved by deploying remotely operated switching devices (ROSDs) envisaging Self-Healing strategies. The network is firstly divided in several zones, having pre existent ROSDs as boundaries and selected the zone with the higher energy not supplied (ENS). Thereafter a failure event on the selected zone is evaluated with a cost/benefit analysis in the entire equipment life cycle. Thereunto cost of energy not supplied, reduction on the electricity sales during the interruption, customer compensations and regulatory penalties/benefits associated with the quality of service are taken into account.

The solution approach was applied to a real Portuguese distribution network for a case study. Reliability improvement as well as a payback period within equipment life cycle was achieved.
\end{abstract}

Index Terms - Self-Healing, Distribution automation, Switching devices allocation, Reliability, Service restoration

\section{INTRODUCTION}

$\mathrm{E}^{\mathrm{s}}$ lectrical power shortages are a major concern in distribution networks. From consumers or Distribution Network Operator (DNO) perspective, interruptions cause major concerns with system stability and reliability. Economically speaking, interruptions cause as well concerns to what it takes to costumer's compensation costs, repairing or providing alternatives for power supply, not even to mention on fear, inconvenience or loss of leisure activities extremely difficult to assess due to its intangible nature [1]. Additionally, the Portuguese DNO faces penalties by not keeping quality of service (QoS) above certain standards, fixed by the regulator [2]. Some studies, such as [3], tie service interruptions to GDP reduction.

Hence, service restoration is required not only to reduce interruption costs and improve QoS, but for keeping the network operating in stable conditions. The author of [4] supports a relation between customer satisfaction and service interruptions. In addition, the author defines service restoration main goal load transferring from the outage area to

R. Moreira is with INESC Porto/FE/UP, Faculty of Engineering, Porto, Portugal (e-mail: ee06162@fe.up.pt)

N. Silva is with EFACEC, Porto, Portugal (e-mail: nuno.silva@efacec.com)

H. Leite is with INESC Porto/FE/UP, University of Porto - Faculty of Engineering, Porto, Portugal (e-mail: hleite@fe.up.pt) other substation, supplying as many customers as possible in the shortest time. In addition to the author of [5] suggestion that distribution network automation is the keystone to improve QoS and reduce maintenance costs.

With Smart Grids deployment and the change of paradigm in distribution networks operation, new capabilities emerge [6]. Self-Healing ability is a suitable example [7]. According to [8] taking advantage of real-time information from scattered sensors and automated controls, the self-healing can automatically avoid and mitigate service interruptions.

Though, to achieve automatic self-healing in a given distribution network, enhanced monitoring and widespread automation is required, along with appropriate allocation of Remotely Operated Switching Devices (ROSDs). These devices along with bidirectional communications schemes enable service restoration algorithms, such as [9], to perform self-healing strategies in service restoration. According to [10] using ROSDs to isolate a fault provides service restoration within 20 seconds, comparing to reclosers operation that takes several minutes, improving this way QoS, as well as reducing interruption costs.

\section{The Challenge}

Empowering the distribution network with a service restoration scheme such as the self-healing entails major investments. Costs with either communications schemes, network adaptation with new infrastructures or new hardware. Besides, distribution network operation may not be technically feasible with the new equipments, likewise ROSDs.

Thus, investment projects as these tackle two major concerns, economical and technical viability. This paper main objective is to address these two concerns, focusing on the Portuguese situation. Develop a systematic tool to assess a cost/benefit analysis with ROSDs deployment in distribution networks. Evaluating therefore the achieved economic and technical benefits envisaging ROSDs operation within selfhealing strategies.

\section{SWitching DEVICES PlaCEMENT IN DistRIBUTION NETWORKS}

The author of [11] describes an analytic methodology to find the "optimal location and number of automation devices". On his work, the author uses two objective functions, reduce interruption costs or maximize automation global benefits. Its 
field application, within the Italian distribution network, according to the author achieved global benefits range from 1,2 to $9 \mathrm{k} €$.

Other approaches based on heuristics have been used to address the problem of finding strategic location to a loadshedding device [12, 13]. These algorithms have different objective functions; some of them optimize reliability indices [13, 14], whereas [12] minimizes outage, maintenance and investment costs using Simulated Annealing. In [15], the authors derive failure rates on trees-caused interruption events and evaluate customer interruption costs using fuzzy systems.

The author of [17] divides the distribution network into zones having as boundaries protection devices, enabling performance analysis of individual zones within the feeder.

\section{A. The Portuguese Distribution Network Operator Vision}

According to [18] the Portuguese DNO uses for objective function the maximization of ENS reduction achieved with a new recloser. Therefore, the annual ENS is evaluated before and after the new switching device, and maximized its reduction. In [19] the same procedure is referenced.

Economical analysis is also centered in ENS reduction. Both authors describe the cost/benefit analysis with a new recloser, taking into account interruptions time reduction and hence reduction on interruption costs. The analysis accounts equipment's life cycle and uses a discount rate of $10 \%$ in order to determine the net present value.

Besides the authors' conformity on the methodology to evaluate reclosers' position, the author of [18] differentiates the method to deploy reclosers from ROSDs. According to the author allocation of ROSD in the network follows an empirical evaluation of possible locations in longer overhead lines or near critical loads.

\section{DEVELOPED METHOdOLOGY}

Some initial assumptions were taken on the methodology. It was assumed that every fault results on a three-phase interruption. Even a single-phase fault was assumed to result on a three-phase interruption. Yet, this principle is easily solved considering a single-phase analysis. Another consideration was the absence of multiple faults in the network. Meaning only one zone in the network is interrupted simultaneously. One more supposition was the consideration of all normally open points (NOPs) to be remotely operated, i.e. with a ROSD already serving as switching device.

The presented method starts by acquiring the network parameters, step (1) in Fig. 1. Achieved with information on lines length and type (overhead or cable), loads, electrical parameters and installed ROSDs.

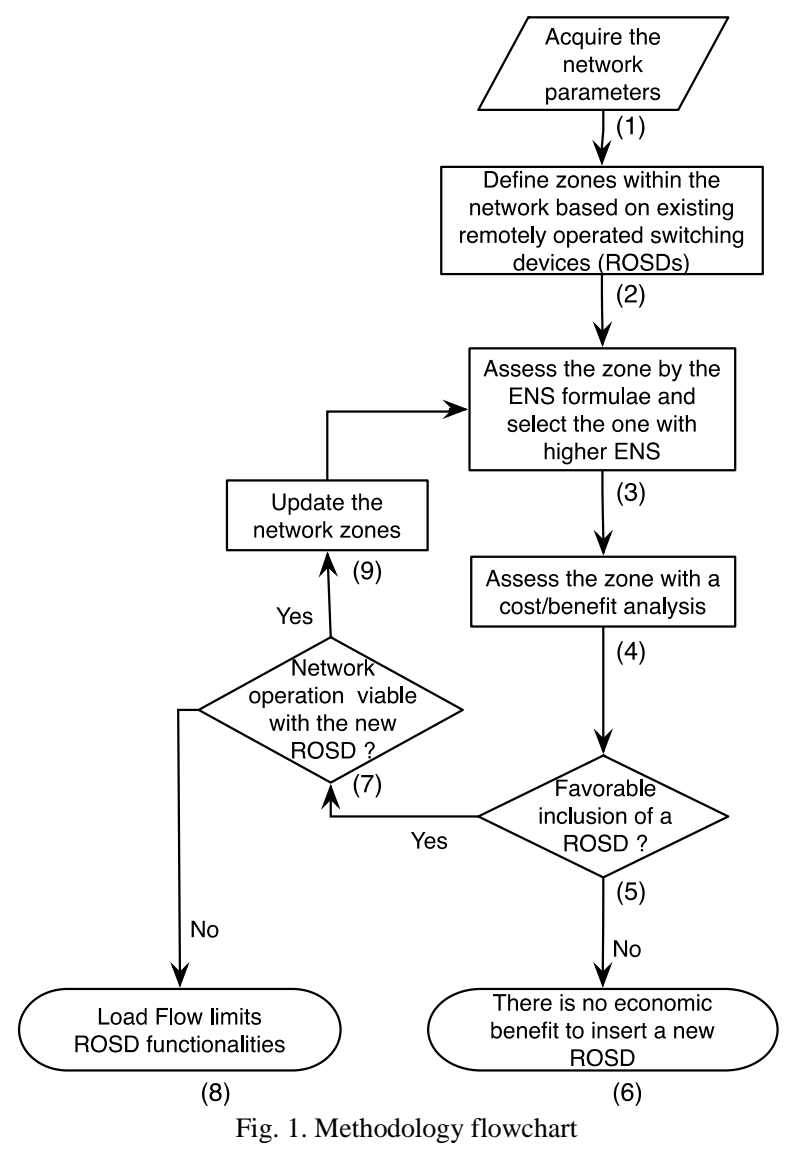

Step (2) uses the information of any existent ROSD in the network. Which enables dividing the network into zones having the preexistent ROSD as boundaries. In case no ROSDs are found in the network, a zone is defined between the primary substation and the NOP at the end of the feeder. Fig. 2 shows an example of a possible MV network divided into several zones, having the preexistent ROSDs as boundaries separating each zone.

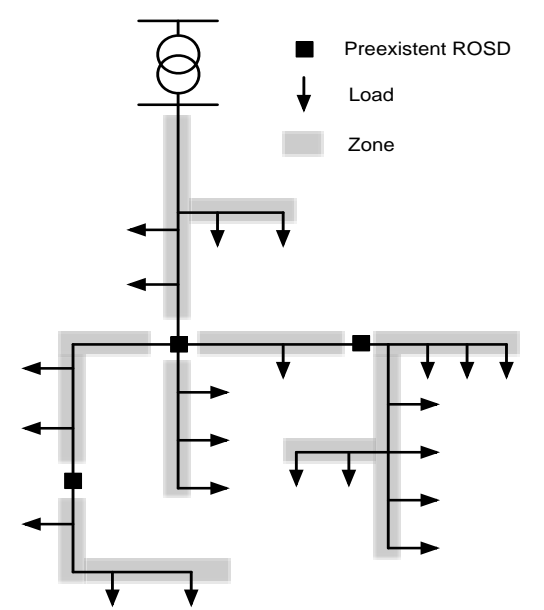

Fig. 2. Example of MV network with several zones

ENS is used to compare each zone in step (3). Therefore the zones are compared by their reliability. The one with higher ENS, and low reliability, may be selected to perform the economical analysis with the new ROSD. Further details 
on this step are given in section A.

Step (4) is used to assess the inclusion of a new ROSD in the selected zone. Done by dividing the zone into two separate parts, regarding total load. Thus, including 1 ROSD results in dividing $50 \%$ of load to each side, 2 ROSD results in $33 \%$ of load and consecutively. Further details on this step are given in section B.

In step (5) the economical viability is evaluated. Having no benefits exceeding the investment cost, in step (6), or if the economical benefits exceed the investment cost, in step (7). Still in step (7), the feasibility of operating the distribution network with the new equipment is evaluated using a Load Flow. Further details on this step are given in section C.

Consequently, the network operation is either possible with the new ROSD, step (9), or having its functionalities limited by the network operation, step (8). With no voltage or current limit violated installing the new ROSD, the network zones should be updated in step (9).

\section{A. Technical Analysis}

The application of penalties from the Portuguese regulator is associated with the annual value of ENS below a reference value. Besides, ENS is easily converted into economical costs using a CENS. Furthermore, QoS in distribution networks is connected to ENS. As a result, evaluation of each zone in step (3) is achieved by calculating the ENS independently. The value of ENS is calculated with (1).

$$
E N S=\chi L \times r \times P \rtimes_{f} \text { [MVA.h], }
$$

where $\lambda$ is the failure rate per kilometer in $[\mathrm{fl} / \mathrm{km}], \mathrm{L}$ the line length in $[\mathrm{km}], \mathrm{r}$ the interruption time in $[\mathrm{h}], \mathrm{P}$ total load in $[\mathrm{MW}]$ and $\mathrm{l}_{\mathrm{f}}$ the load factor.

\section{B. Economical Analysis}

Planning investments are usually made foreseeing several years of network operation. Since this method presents an economical analysis, in the same way it should consider several years of analysis. Hence, the economical analysis is made foreseeing the ROSDs operation in their entire life cycle, taking into account load growth rates and tariffs growth rate.

In the same way [12] uses the CENS to evaluate the economical cost of interruptions to costumers this method takes into account the CENS. Also, using ENS to assess zones reliability, a linkage is made between economic and technical benefits. Equation (2) presents the calculation of CENS.

$$
C E N S=T I E P I \times P \rtimes_{f} \times V_{E N S} x_{C}[€],
$$

where TIEPI is the interruption equivalent time for the installed power in $[\mathrm{h}], \mathrm{P}$ is the installed power $[\mathrm{MW}], \mathrm{l}_{\mathrm{f}}$ the load factor, $V_{\text {ENS }}$ is the ENS value in $[€ / \mathrm{kW} . \mathrm{h}]$ and $\mathrm{i}_{\mathrm{C}}$ is the load growth rate.

During the fault utilities have their profits reduced, since there is no electricity sales, as customers are not supplied. Hence utilities are also affected with loss of revenue during service interruptions. Loss of revenue (LR) is calculated with (3).

$$
L R={ }_{i=1}^{x} \operatorname{TIEPI} \times P_{i} \rtimes_{f} \rtimes_{i} \rtimes_{t}[€],
$$

where TIEPI is the interruption equivalent time for the installed power in $[\mathrm{h}], \mathrm{P}_{\mathrm{i}}$ is the contracted power for customer $i$ in $[\mathrm{kVA}], \mathrm{l}_{\mathrm{f}}$ is the load factor, $t_{\mathrm{i}}$ is the tariff value for customer $i$ and $i_{t}$ is tariff growth rate.

Violating the interruptions frequency and interruptions total duration, each year, results in penalties to the DNO. In the Portuguese situation these penalties are regulated and calculated according to (4) and (5), respectively for interruptions frequency and interruptions total duration.

$$
I F=\left(N I \quad N I_{R E F}\right) \times V_{I F}[€],
$$

where $\mathrm{NI}$ is the number of interruptions, $\mathrm{NI}_{\mathrm{REF}}$ is the reference number of interruptions defined by the regulator and $\mathrm{V}_{\mathrm{IF}}$ is the unitary value of compensation for exceeding the number of interruptions limit, in $[€]$.

$$
I D=\left(D I \quad D I_{R E F}\right) \times P \times V_{I D}[€],
$$

where DI is the total interruptions duration in $[\mathrm{h}], \mathrm{DI}_{\mathrm{REF}}$ is the reference for total interruptions duration defined by the regulator in $[\mathrm{h}], \mathrm{P}$ is the contracted power in $[\mathrm{kW}]$ and $\mathrm{V}_{\mathrm{ID}}$ is the unitary value of compensation for exceeding the total duration of interruptions limit, in $[€ / \mathrm{kWh}]$.

Hence, penalties total cost is given by (6).

$$
P C=I F+I D[€],
$$

Likewise the regulation of interruptions frequency and duration and consequent application of penalties to the DNO, annual value of ENS suffers a similar mechanism of regulation. In short, each year the regulator declares a reference value for the ENS and if each year the annual ENS surpasses this reference value the DNO incurs in penalties, in the same way if the annual ENS stays below this reference value a subsidy is given to the DNO. Fig. 3 illustrates the way this regulation mechanism works in the Portuguese situation.

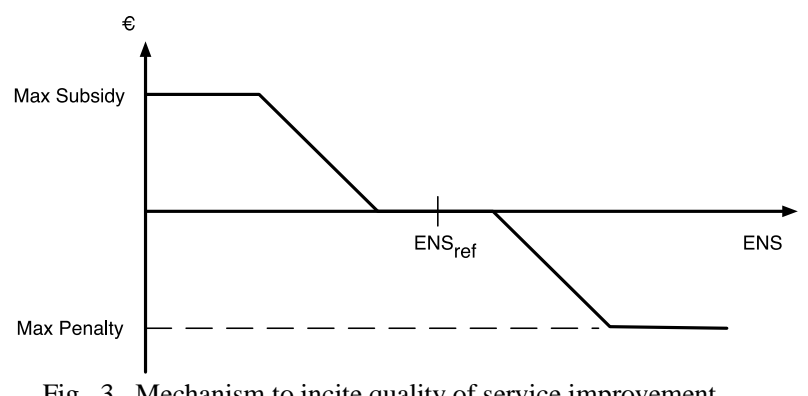

Fig. 3. Mechanism to incite quality of service improvement.

Equations (7) and (8) show the formulation when the ENS is below the reference value (subsidy situation) and ENS is above the reference value (penalty situation).

$$
Q S R=\operatorname{Min}\left(Q_{\text {max }} ;\left(E N S_{\text {ref }} \cdot i_{E N S} \quad V \quad E N S\right) \cdot V_{E N S}\right)[€],
$$

where $\mathrm{QSR}_{\max }$ is the maximum value for the subsidy in $[€]$, $\mathrm{ENS}_{\text {ref }}$ is the reference value of ENS stated by the regulator in $[\mathrm{kW} . \mathrm{h}], \mathrm{i}_{\mathrm{ENS}}$ is the $\mathrm{ENS}_{\text {ref }}$ reduction rate, $\Delta \mathrm{V}$ is a tolerance 
value in [kW.h], ENS is the annual value of ENS in [kW.h] and $\mathrm{V}_{\mathrm{ENS}}$ is the value of ENS in [€/kW.h].

$$
Q S R=\operatorname{Max}\left(Q S R_{\text {min }} ;\left(E N S_{\text {ref }} \cdot i_{E N S}+V E N S\right) \cdot V_{E N S}\right)[€] \text {, (8) }
$$

where $\mathrm{QSR}_{\min }$ is the maximum value for the penalty in $[€]$.

Placing a new ROSD in the selected zone will create a separation into two new zones. Since load is not evenly distributed in the network, dividing equally $50 \%$ of load to each new zone is usually impracticable. Therefore the economical analysis should consider an interruption in the zone with higher amount of load, resulting this way in higher ENS.

Each of these economical components should be compared to the initial scenario, with no ROSD. Thus the result of equations (2), (3), (6) and (7) or (8) with a new ROSD has to be compared to the previous result of no ROSD installed, i.e. initial minus final value for each component. Resulting this way in costs reduction, since there are no direct profits in installing a new ROSD.

For the investment scenario two types of equipment's were used, reclosers for overhead lines and a Distribution Transformer Controller (DTC) [10] for underground networks. Within the price it should be included the maintenance cost, installation and acquisition cost. Maintenance costs will be calculated according to the acquisition cost, used in [19] analysis as $2 \%$ of acquisition costs.

$$
I=C_{A}+C_{l}+0,02 \times C_{A}[€],
$$

where $C_{A}$ is the acquisition cost, $C_{I}$ is the installation cost and 0,02. $\mathrm{C}_{\mathrm{A}}$ are the maintenance costs.

\section{Load Flow validation}

Even with economic viability from installing a new ROSD in the distribution network, its operation has to be validated regarding voltage and current limits. Since service restoration within self-healing strategies foresees load transfers to other substation, conductor's current has to be kept under their capacity. In the same way, voltage drop on every load point needs to be over specified limits.

In order to guarantee ROSD full operation within selfhealing strategies in coordination with feeder normally open points (NOPs), the network needs to be submitted to a load flow calculation and validation. Doing a load transfer, in the worst-case scenario of energy demand, conductor's current capacity and voltage drop in load points has to be within their specific limits. Situations are, when in the presence of nearby distributed generation (DG), current limit violations are solved considering DG power injection.

\section{CASE STUdY}

Applying the developed methodology to a case study has essentially as main objective confirm it within a real scenario. Therefore, it was employed a real MV distribution network.

In particular, a small section of the Portuguese south region distribution network was employed. Connecting 3 primary distribution substations $(60 \mathrm{kV}-15 \mathrm{kV})$, with installed power of 10, 20 and 63 MVA, 2 wind farms with 50 and 55 MVA, 11 NOPs and secondary distribution substations with total installed power of 80,94 MW. Fig. 4 show the network employed.

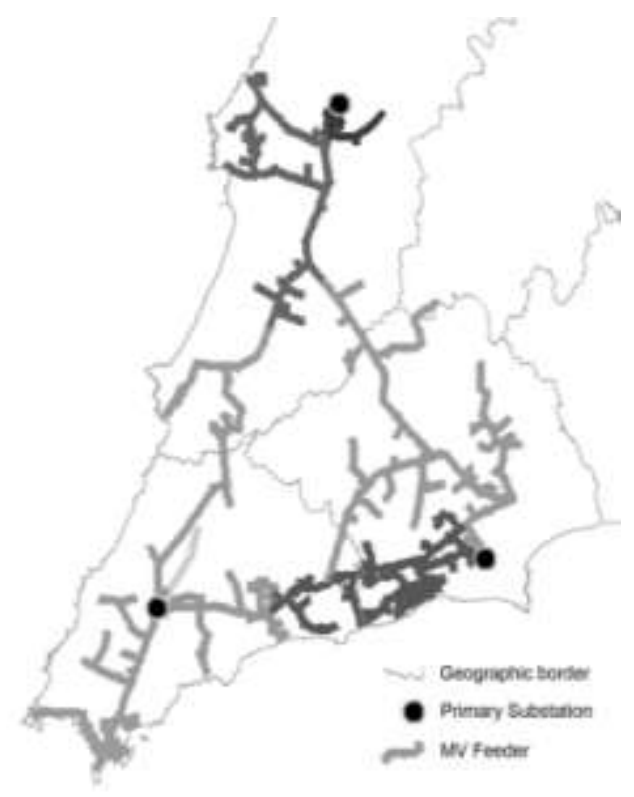

Fig. 4. Distribution network used for the case study.

The employed network is on its majority composed of overhead feeders, with just 2 underground feeders. Apart from the numerous reclosers spread through the overhead feeders, there is any ROSD in the entire network. Therefore, zones division envisioned at Fig. 1, step (2), results in defining each zone starting in the substation and ending at the feeder NOP. Hence, the number of total zones in this case study equals the number of feeders, i.e. 8 zones/feeders.

\section{A. Zones Evaluation upon ENS calculation}

With the network divided in zones and using equation (1) to assess ENS, the results were:

TABLE I ENS results for all zones

\begin{tabular}{c|c|c|c} 
Zone & Length [m] & Load [MW] & ENS [MW.h] \\
\hline A & 32282 & 13,41 & 31,6 \\
\hline B & 27830 & 11,95 & 24,3 \\
\hline C & 19075 & 13,91 & 19,4 \\
\hline D & 8173 & 16,84 & 10,0 \\
\hline E & 8350 & 16,19 & 9,9 \\
\hline F & 9383 & 7,10 & 4,9 \\
\hline G & 1191 & 1,55 & 0,1 \\
\hline H & 8377 & 0 & 0,0
\end{tabular}

Failure rate and average interruption time needed for the ENS calculation came from the DNO's 2009 quality of service report for the Portuguese south region, i.e. the same distribution network region:

- $\lambda=0,0973$ [failures $/ \mathrm{km}$;

- $\mathrm{r}=2,5[\mathrm{~h}]$.

A $30 \%$ load factor calculated from the average peak demand in all network MV/LV substations was used in the calculation.

Zone $\mathrm{H}$ relates to an overhead line solely to connect one of the wind farms, having no loads, this way its ENS is as presented 0 [MW.h]. 
Following step (3) from Fig. 1 the zone with higher ENS should be selected. Therefore, from TABLE I, zone A is the one with higher ENS and its location is presented in Fig. 5.

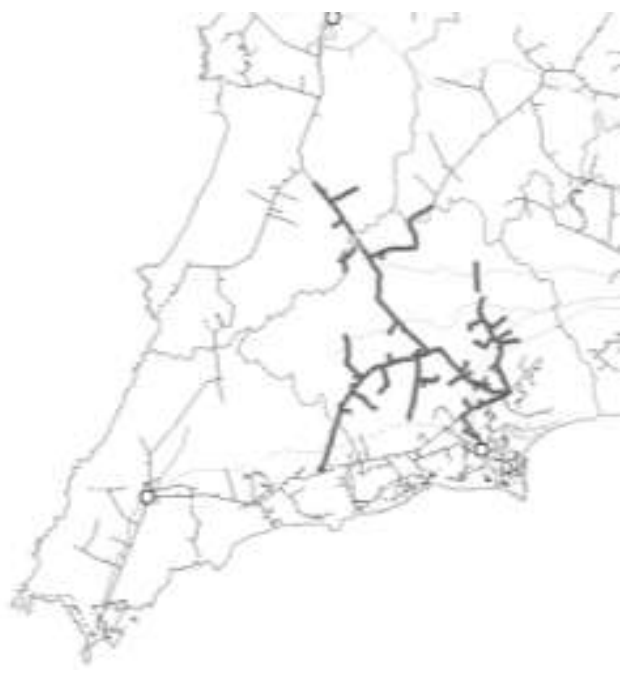

Fig. 5. Selected zone with the higher ENS value.

The feeder has $32282[\mathrm{~m}]$ of total length, 9,37 [MW] in public MV/LV substations and 4,04 [MW] in private ones, a wind farm with 55 [MVA] of installed power and 3 NOPs.

\section{B. Economical Assessment within Equipment's Life Cycle}

The economical analysis used 4 different scenarios of investment: 1, 2, 3 or 4 ROSD. Hence, installing a ROSD in the selected zone causes its division in new zones. For instance in the scenario of 1 ROSD it would split the zone in 2 , as for the scenario of 4 ROSDs it would split the zone into 5 new zones, regarding total load.

Since loads are not evenly distributed, the zone division for the 4 scenarios resulted in:

- 1 ROSD - 55\% and $45 \%$ of load to each side;

- 2 ROSDs $-36 \%, 26 \%$ and $38 \%$ of load to each side;

- 3 ROSDs $-36 \%, 26 \%, 16 \%$ and $22 \%$ of load to each side;

- 4 ROSDs $-18 \%, 18 \%, 26 \%, 16 \%$ and $22 \%$ of load to each side.

Therefore the costs reduction should be assessed for the worstcase scenario, i.e. for the higher percent of affected load with an interruption $(55 \%, 38 \%, 36 \%$ and $26 \%$ in the 4 investment scenarios).

As stated in section IV. B. equipment's have a 20 year's life cycle, under regular maintenance. Then economical analysis should also be assessed for a 20 -year period. Though, in order to simplify results presentation, only the first year results will be presented thoroughly.

\section{1) Cost of Energy Not Supplied}

CENS calculation is given by equation (2), presented in section IV. B. Results for all the investment scenarios are shown in TABLE II, only for the first year of analysis.

TABLE II

CENS for all investment scenarios, for the $1^{\text {st }}$ year.

\begin{tabular}{c|c|c|c|c|c} 
& 0 ROSD & 1 ROSD & 2 ROSD & 3 ROSD & 4 ROSD \\
\hline CENS [€] & 12188 & 6749 & 4613 & 4357 & 3127
\end{tabular}

CENS calculation with: a TIEPI of $121 \mathrm{~min} /$ year from the DNO's 2009 quality of service report for the Portuguese south region distribution network, the unitary cost of ENS $\left(\mathrm{V}_{\mathrm{ENS}}\right)$ of $1,5 € / \mathrm{kWh}$ defined by the Portuguese regulator and a $3,1 \%$ annual demand growth rate to calculate CENS for the remaining 19 years.

Note that CENS reports to an interruption cost, therefore the profit is calculated subtracting the final CENS to the original value, i.e. with a 3 ROSDs scenario profit is $12188 €$ minus $4357 €$, resulting in $7831 €$ of benefit.

\section{2) Loss of Revenue}

Loss of electricity revenue during the interruption is given by equation (3), presented in section IV. B. Results for all the investment scenarios are shown in TABLE III, only for the first year of analysis.

TABLE III

Loss of Revenue for all investment scenarios, for the $1^{\text {st }}$ year.

\begin{tabular}{c|c|c|c|c|c} 
& 0 ROSD & 1 ROSD & 2 ROSD & 3 ROSD & 4 ROSD \\
\hline LR $[\epsilon]$ & 886 & 477 & 424 & 306 & 134
\end{tabular}

LR calculation with: customers average contracted power of 6,9 kVA and $250 \mathrm{kVA}$ for LV and MV costumers, tariffs prices for $\operatorname{LV}(0,1326 € / \mathrm{kWh})$ and $\mathrm{MV}(0,0876 € / \mathrm{kWh})$ customers defined by the regulator and a 2,5\% annual tariffs growth rate to calculate LR for the remaining 19 years.

Note that LR reports to an interruption cost, therefore the profit is calculated subtracting the final LR to the original value, i.e. with a 2 ROSDs scenario the profit is $886 €$ minus $424 €$, resulting in $462 €$ of benefit.

\section{3) Costumers Compensations}

Costumers compensations is given by equations (4) and (5), and their sum by (6).

The number of interruptions and their total duration, from the DNO's 2009 quality of service report for the Portuguese south region distribution network, were 3 faults/year and 121 min/year. Since these quantities do not exceed the limits of 16 faults/year and $480 \mathrm{~min} / \mathrm{year}$, there were no costumers' compensations. Resulting in $0 €$ for all investment scenarios, even for the original scenario of 0 ROSD.

\section{4) Incentive to Improve Quality of Service}

Mechanism to incite quality of service improvement is given by equation (7) in case annual ENS is below the reference value or by equation (8) if annual ENS is above the reference value. Results for all investment scenarios are shown in TABLE IV, only for the first year of analysis.

TABLE IV

Incentive to improve QoS for all investment scenarios, for the $1^{\text {st }}$ year.

\begin{tabular}{c|c|c|c|c|c} 
& 0 ROSD & 1 ROSD & 2 ROSD & 3 ROSD & 4 ROSD \\
\hline QSR [€] & -4214 & -5613 & -5942 & -5975 & -6100
\end{tabular}

QSR calculation with: maximum value of subsidy/penalty of $23047 €$, reference value of ENS (ENS ${ }_{\text {ref }}$ ) of $0,0134 \%$ of the total energy supplied within the feeder, $\mathrm{ENS}_{\text {ref }}$ reduction rate of $5,8 \%, \Delta \mathrm{V}$ of $12 \%$ of $\mathrm{ENS}_{\text {ref }}$ and $\mathrm{V}_{\mathrm{ENS}}$ of $1,5 € / \mathrm{kWh}$.

Note that QSR values are all negative, meaning a subsidy was applied. Since a cost notation is used in all economical analysis, and with the QSR calculation results a subsidy for 
the DNO, the negative sign is used. Nevertheless the profit of having a new ROSD is given by the same way as the previous examples, i.e. with a 4 ROSDs scenario the profit is $-4214 €$ minus $-6100 €$, resulting in $1886 €$ of benefit.

5) Costs of Investment

As the selected zone is entirely made up overhead lines, the DTC solution is not suitable. Therefore, all ROSDs are reclosers with the necessary equipment for remote operations. According to a supplier, a ROSD single unity costs $20096 €$, given by equation (9) in section IV. B. The total cost for each investment scenario is thus given by single unity cost times number of units, for instance for 2 ROSDs results in 2 time 20 $096 €$, totaling $40192 €$.

\section{6) Overall Results}

Since the economical analysis should be formulated for all equipment's life cycle (20 years in this study), a discount rate should be used and consequently the net present value (NPV).

Hence, a discount rate of $10 \%$ was employed to calculate the NPV for the 20 years of analysis. This way, a payback period could also be determined. In Fig. 8 both payback period and NPV are presented for all investment scenarios.

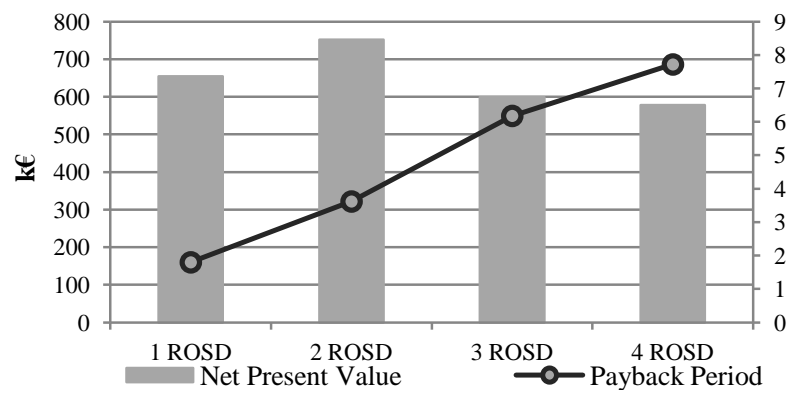

Fig. 6. Net Present Value and Payback period for all investment scenarios.

\section{Load Flow Results}

The Load Flow calculation was achieved using a SCADA/DMS software with a specific tool for Load Flow analysis. Namely the ScateX+, also used by the Portuguese DNO.

In order to evaluate any technical violations with the inclusion of a new ROSD, the following scenario was applied:

- No power injection from the wind farm within the zone;

- NOP closure and consequent ROSD opening.

It was selected the ROSD which on its opening results in the major load transfer.

The 4 ROSDs scenario was firstly evaluated, closing the NOP at the end of the feeder and pretended a fault on the beginning of the feeder resulting on the first ROSD opening. Meaning, approximately $4 / 5$ of total load were transferred to the other substation. Fig. 7 shows the feeder schematic after closing the NOP and opening the opposite ROSD, at the beginning of the feeder (see Fig. 5 for comparison).

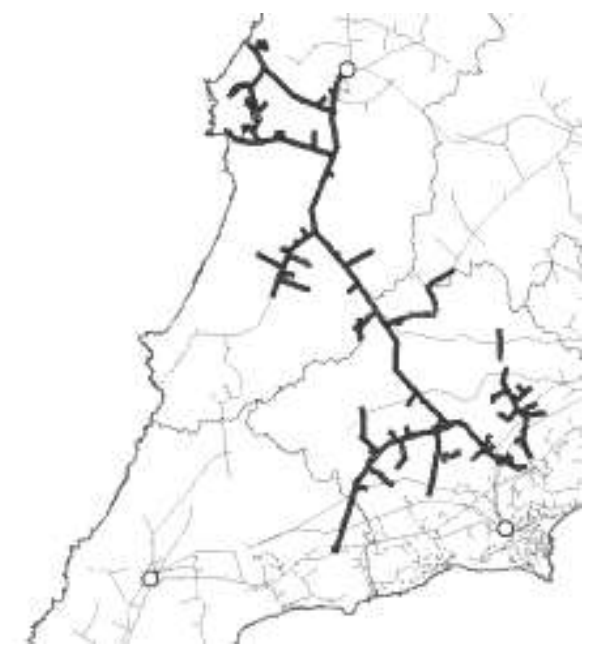

Fig. 7. Evaluated feeder after NOP closure and ROSD opening.

\section{CRITICAL ANALYSIS}

With the 20-year's results each economical component contribution was evaluated in the overall amount. Analyzing the average percent for each economical component within the 4 investment scenarios a major contribution was noticed, Fig. 8.

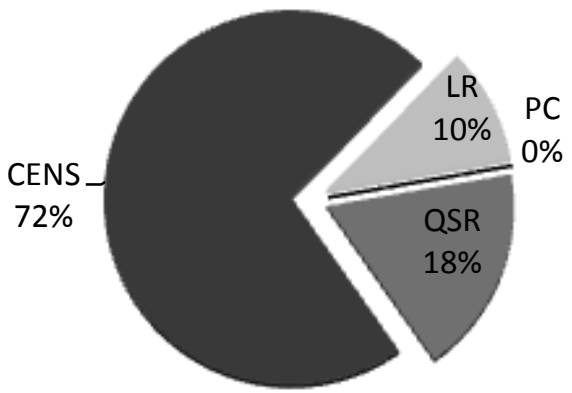

Fig. 8. Contribution of each economical component in the overall amount.

CENS plays a major role in the economical analysis. The reason behind that relies on the greater value of $\mathrm{V}_{\mathrm{ENS}}$, the unitary cost of ENS equal to $1,5 € / \mathrm{kWh}$. Meaning, it is 10 times greater than LV tariff $(0,1326 € / \mathrm{kWh})$ and 17 times greater than MV tariffs $(0,0876 € / \mathrm{kWh})$. On the other side, since the mechanism to incite QoS improvement is already positive, adding ROSDs to the zone bring small benefits compared to CENS reduction.

Since TIEPI is the used time for modeling average total interruption duration in a year, and being used for all the economical components calculation, its impact should be considered. Therefore it was determined its influence in the payback period, ranging its value from $-50 \%$ to $+50 \%$ (61 to $182 \mathrm{~min} /$ year). The results are shown in Fig. 9. Note that, for the $3^{\text {rd }}$ and $4^{\text {th }}$ scenario, a reduction in TIEPI to 50\% implies that the payback period is no longer within the 20 years life cycle. 


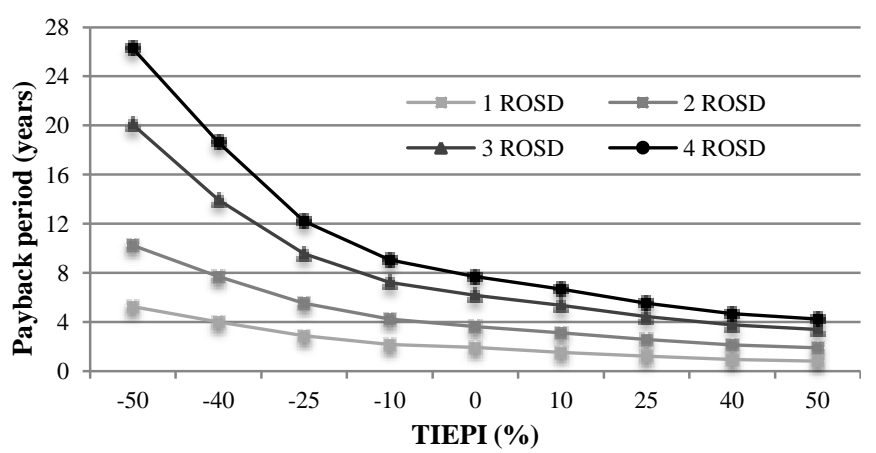

Fig. 9. TIEPI's influence in payback period.

Technical benefits were similarly evaluated with the installation of new ROSDs. As described in section V. B. the zone division with a new ROSD is hardly even, for instance with 1 ROSD resulted in a $45-55 \%$ division. This way, the worst-case scenario would be a fault on the $55 \%$ side, interrupting the most load, as a best-case scenario would be an interruption on the $45 \%$ side.

Presented in Fig. 10, ENS reduction was increasingly better the more ROSDs were invested. This was a consequence of reducing the zone in smaller sections each time a new ROSD was installed. Note that for 3 and 4 ROSDs the best scenarios have the same value of ENS, resulting from the same load division of $16 \%, \mathrm{~V}$. B.

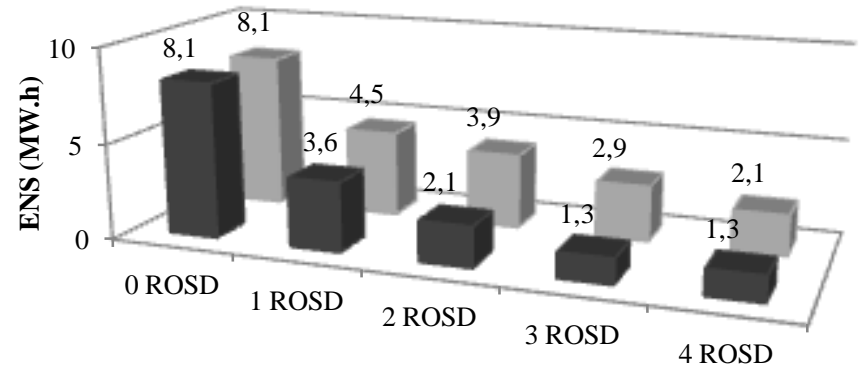

Best Case Scenario Worst Case Scenario

Fig. 10. ENS reduction for 1, 2, 3 or 4 ROSDs.

A similar improvement was achieved on the number of affected costumers with a fault, Fig. 11. Still, since zones have different number of costumers, besides ENS equals 1,3 [MW.h] with 3 or 4 ROSD (for the best scenario), the number of customers suffer a slight reduction.

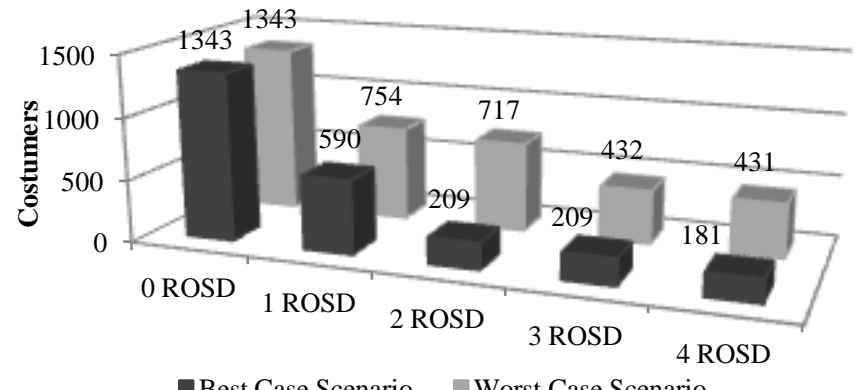

- Best Case Scenario Worst Case Scenario

Fig. 11. Number of affected customers for 1, 2, 3 or 4 ROSDs.

\section{FINAL REMARKS}

Implementing a Self-Healing strategy results in reducing the circuit breakers reclosing operations, since there is no
Voltage-Time logic associated with the ROSDs operation. This comes with the dispersion of sensors through the network, indicating the fault location. As outcome, circuit breaker detrition is reduced since reclosing operations in the presence of short circuit are reduced. This way, strategic deployment of ROSDs in the network is essential to improve quality of service.

\section{A. Conclusions}

Following the analysis, a significant quality of service improvement is feasible with ROSDs installation. According to Fig. 10 and Fig. 11, the number of affected costumers as well as the ENS suffers a reduction.

Other major conclusion is the CENS major role in the economic analysis. Due to its value of $1,5[€ / \mathrm{kW} . \mathrm{h}]$, ten times greater than the LV tariff, and consequently its major influence in the payback period may compromise the viability of the economic analysis. Still, relative to the economical analysis, a major influence in the payback period occurs with the TIEPI variation. As Fig. 9 shows, a reduction of $50 \%$ in TIEPI means that the payback period, for this case study, is above 20 years, i.e. over the equipment life cycle.

The load flow validation revealed itself essential in order to confirm full operation of the new ROSD in the network. This step not only confirms the economical results achieved with the case study, meaning that in the presence of a fault, all functionalities of the new installed ROSD are available within Self-Healing strategies. On the contrary, ignoring this step of validating all functionalities of the new ROSD in the network could result in exceeding lines current flow capacities and/or voltage drop limits violation. Resulting, this way in the infeasibility to use that new ROSD to proceed to a service restoration within a Self-Healing strategy.

Having a generic tool, such as this one, enables this kind of analysis to be applied either to overhead or underground lines, as well as radial, open or closed meshed networks. Likewise the opportunity to adapt TIEPI values, failure rates, CENS and LV and MV tariffs to different scenarios of analysis, such as a network analysis in different geographic regions.

Summing up, all the main conclusions can be grouped as:

- Significant quality of service improvement with ROSD deployment;

- Cost reduction is also achieved using ROSD for a service restoration envisaging Self-Healing strategies;

- The economic viability of such project has been proved in the case study, having the payback period within the end of the ROSDs life cycle.

\section{B. Major Contributions}

Since the deployment of ROSDs envisages service restoration under Self-Healing strategies, the time required to isolate a fault and restore the service to customers is significantly less than using reclosers with V-T logic.

Using this systematic tool to assess strategic positions to deploy a new ROSD, the number of possible affected customers is known integrating the presented results such as the exact position of the ROSD installation. Consequently, knowing the number of affected customers and their installed power, one may also know the ENS with a fault. 
Besides the costumers' costs, usually taken into account by other authors, this work includes as well the DNO associated costs. Specifically bringing into the calculation reduced revenue from electricity sales during a service interruption and the regulatory penalties associated with low quality of service provided to costumers. In order to assess regulatory penalties to the DNO, customers division is achieved by their voltage level. This way costumers connected to the MV level were given a higher significance compared to LV costumers.

\section{Methodology Limitations}

A limitation with the methodology was found during the case study. The loads quantity within a zone is not taken into account in the ENS formulae, and consequently not evaluated to select a strategic location for the ROSD. A given example is having two zones, with same length, failure rate, average interruption time and total amount of load but different number of loads (MV-LV substations). Resulting in equal values of ENS and therefore both should be selected for a ROSD installation. Though the zone with higher number of loads should be preferred resulting in a service restoration to a higher number of costumers. This situation is not differentiated in this methodology.

Planning results achieved with the analysis may be compromised with the site's geography, i.e. mounting a ROSD in a specific pole may not be easily accessible as mounting it in a neighborhood pole. Meaning, field teams easier do installation and maintenance operations on the ROSD. An answer may be found integrating this methodology into a GIS (Geographic Information System) and find a compromise to the obtained results.

\section{REFERENCES}

[1] R. Billinton and R. Allan, "Reliability Evaluation of Power Systems," 2nd ed., Plenum Press New York, 1996, pp. 443-449.

[2] Direcção-Geral de Geologia e Energia, "Regulamento da Qualidade de Serviço", Diário da República - II Série nº48, 8 March 2006.

[3] Momoh, J.A. and A.C. Caven. "Evaluation of cost benefit analysis for the reconfigured distribution system". in Transmission and Distribution Conference and Exposition, 2003 IEEE PES. pp. 643-648 vol.2, 2003.

[4] Toune, S., et al., Comparative study of modern heuristic algorithms to service restoration in distribution systems. Power Delivery, IEEE Transactions on, 2002. 17(1): p. 173-181.

[5] Gill, H.M. "Smart Grid distribution automation for public power". in Transmission and Distribution Conference and Exposition, 2010 IEEE PES. pp. 1-4, 2010.

[6] N. Silva, P. Lopes and et al., "New Control and Management Architectures for Active Distribution Networks," in POWERGRID Europe, Cologne, Germany, 2009.

[7] A. Bernardo, N. Silva and et al., "Preventive Assessment for Combined Control Centre and Substation-Centric Self-Healing Strategies," presented at 21st International Conference on Electricity Distribution, Frankfurt, 2011

[8] Tianyou, L. and X. Bingyin. "The self-healing technologies of smart distribution grid". in Electricity Distribution (CICED), 2010 China International Conference on. pp. 1-6, 2010.

[9] Matos, M.A. and P. Melo. "Multiobjective reconfiguration for loss reduction and service restoration using simulated annealing". in Electric Power Engineering, 1999. PowerTech Budapest 99. International Conference on. pp. 213, 1999.

[10] Silva, N., et al., "New Approach to Self-Healing on the Context of SmartGrids", PowerGrid Europe Amsterdam, Junho 2010.

[11]Noce, C. "Optimal placement of automation devices in Enel distribution network". in Electricity Distribution - Part 1, 2009. CIRED 2009. 20th International Conference and Exhibition on. pp. 1-4, 2009.
[12]R. Billinton and S. Jonnavithula, "Optimal Switching Device Placement in Radial Distribution Systems," IEEE Transaction on Power Delivery, vol. 11, no. 3, pp. 1646-1651, Jul 1996.

[13] Y. Wenyu, S. Meng and et al., "Optimal Allocation of Switches in Distribution Networks," in 5th WCICA, 2004, pp. 5155-5159.

[14]P. Carvalho, A. Cerejo da Silva and et al., " A Decomposition Approach to Optimal Remote Controlled Switch Allocation in Distribution Systems," IEEE Transactions on Power Delivery, vol. 20, no. 2, pp. 1031-1036, Apr 2005.

[15] W. Kurutach and Y. Tuppadung, "Feeder-Switch Relocation Based upon Risk Analysis of trees-Caused Interruption and Value-Based Distribution Reliability Assessment," in IEEE Region 10 Conference, 2004, pp. 577-580.

[16] G. Cheng, O. Das and et al., "Comparative Study of Heuristics for Reliability Optimization of Complex Systems," in 23rd CCECE, 2010, pp. 1-4.

[17]A. Pais da Silva, "Framework for Analysing Performance Driven Distribution Network Investment Strategies," PhD Thesis submitted to Imperial College London, United Kingdom, 2008.

[18] Rocha, N.A.d.C.P.d., "Pesquisa, Detecção e Reparação de Avarias em Redes de Distribuição MT e BT", Relatório de Estágio na FEUP, 2002.

[19]Lourenço, J.L., "Pesquisa, Detecção e Reparação de Avarias na Rede de Distribuição MT/BT", Relatório de Estágio na FEUP, 2001.

\section{BIOGRAPHIES}

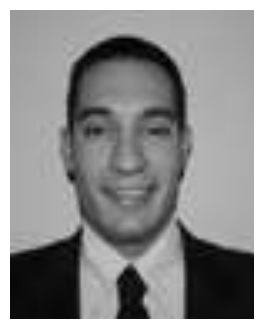

Roberto Moreira is pursuing MSc Degree at University of Porto - Faculty of Engineering and he is developing his work at EFACEC.

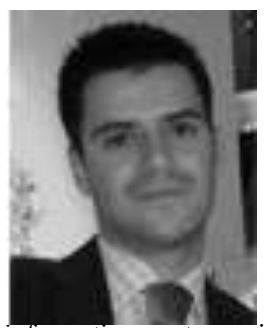

Nuno Silva (M' 04) graduated from the University of Porto in 2003 and finished his $\mathrm{PhD}$ in Electrical Engineering at the Control and Power Group, Imperial College London in 2009. He now works at EFACEC, the largest Portuguese group in the field of electricity. $\mathrm{He}$ is currently the Smart Grids Architecture Lead at the Automation Business Unit being involved in several smart grids initiatives and electrical mobility projects. Energy and engineering solutions such as automation, maintenance, information systems, innovation and project management are his areas of activity. His research interests include planning and operation of distribution networks, distributed generation, renewable energies, Smart Grids, selfhealing, electric vehicles integration and economics of distribution networks.

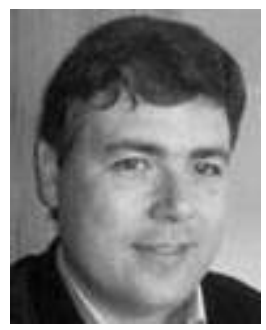

Hélder Leite received his Electrical Engineering degree from the University of Porto, Portugal in 2000 and the PhD degree in Electrical Engineering from The University of Manchester, UK, in 2004. H. Leite joined University of Porto, Portugal as a Lecturer in 2005. His research interests include Distribution Generation Integration, Electric Power Systems and Power Systems Protection. 